\title{
Effects of Anserine on the Renal Sympathetic Nerve Activity and Blood Pressure in Urethane-Anesthetized Rats
}

\author{
M. TANIDA ${ }^{1,2,3}$, J. SHEN ${ }^{2,3}$, D. KUBOMURA ${ }^{4}$, K. NAGAI ${ }^{2,3}$ \\ ${ }^{1}$ College of Life Sciences, Ritsumeikan University, Kusatsu, Shiga, Japan, ${ }^{2}$ Institute for Protein \\ Research, Osaka University, Suita, Osaka, Japan, ${ }^{3}$ ANBAS Corporation, Kita-ku, Osaka, Japan, \\ ${ }^{4}$ Yaizu Suisankagaku Industy CO., Ltd., Yaizu, Shizuoka, Japan
}

Received June 6, 2008

Accepted March 10, 2009

On-line June 19, 2009

\section{Summary}

Previous studies have demonstrated that central injection of L-carnosine ( $\beta$-alynyl-L-histidine), dipeptide synthesized in mammalian muscles, affects renal sympathetic nerve activity (RSNA) and blood pressure (BP) in anesthetized rats. In the present study, using urethane-anesthetized rats, we examined the dose-dependent effects of intravenous (IV) injection of various doses of anserine, dipeptide of similar structure to L-carnosine, on RSNA, BP and heart rate (HR). We found that injection of a low dose of anserine $(1 \mu \mathrm{g})$ significantly suppressed RSNA, BP and HR. Conversely, a high dose $(1000 \mu \mathrm{g})$ of anserine significantly elevated RSNA, BP and HR. Pretreatment with lateral cerebral ventricular (LCV) injection of thioperamide, a histaminergic $\mathrm{H}_{3}$-receptor antagonist, eliminated the effects of a low dose of anserine on RSNA, BP and HR. LCV injection of diphenhydramine, a histaminergic $\mathrm{H}_{1}$-receptor antagonist, abolished the effects of a high dose of anserine on RSNA, BP and $H R$. These findings suggest that anserine affects RSNA, BP and $\mathrm{HR}$ in a dose-dependent manner, and that the histaminergic nerve may be involved in the dose-different effects of anserine in rats.

\section{Key words}

Autonomic nerve $\bullet$ Cardiovascular function • Histaminergic nerve

- Thioperamide • Heart rate

\section{Corresponding author}

M. Tanida, College of Life Sciences, Ritsumeikan University, 1-1-1 Noji-kita, Kusatsu, Shiga, 525-8577, Japan. Fax: +81-77561-2629. E-mail: mtanida@sk.ritsumei.ac.jp

\section{Introduction}

Chicken soup is known worldwide for its health benefits. In Asian countries, essence of chicken muscles is used as a traditional health food for recovery from physical fatigue, mental stress, and cardiovascular disease (Nagai H et al. 1996, Matsumura et al. 2002, Lo et al. 2005). In fact, long-term supplementation of chicken muscle essence has been shown to attenuate the development of hypertension in spontaneous hypertensive rats (Matsumura et al. 2002). However, the active ingredient in the chicken muscle essence is unknown. Previous studies have shown that this essence is abundant in dipeptides, anserine, and L-carnosine (Drummond 1917, Sato et al. 2008). The structure of anserine ( $\beta$-alanyl-1-N-methyl-histidine), which is synthesized and released into the blood by the skeletal muscles of vertebrates, is similar to that of L-carnosine ( $\beta$-alynylL-histidine). The concentration of L-carnosine in the skeletal muscles of hypertensive rats is markedly low (Johnson and Hammer 1992). Moreover, our recent observations of suppression or elevation of sympathetic nerve activity supplying the kidney and brown adipose tissue with low or high doses of L-carnosine, respectively, indicate that L-carnosine, which affects the autonomic nerves, changes the blood pressure (BP) and body temperature in a dose-dependent manner (Tanida et al. 2005, 2007a). However, it is still unclear whether the administration of various doses of anserine change the $\mathrm{BP}$ and renal sympathetic nerve activity (RSNA) which plays an important role in BP 
regulation (Morgan et al. 1995).

Because the degradation enzyme of L-carnosine is localized in the hypothalamic region of rat brain (Otani et al. 2005), it was suggested that L-carnosine functions as a cardiovascular regulator via the central nervous system. Central neural histamine is localized in the histaminergic tuberomammillary nucleus (TMN), a site of origin for histamine neurons (Watanabe et al. 1984), and is involved in the regulation of cardiovascular functions via histaminergic receptors (Tanida et al. 2007b). Our previous finding that a pretreatment with lateral cerebral ventricular (LCV) injection of thioperamide (an antagonist of histaminergic $\mathrm{H}_{3}$-receptor) inhibited the effects of a low dose of histamine on RSNA and BP, and that a pretreatment with LCV preinjection of diphenhydramine (an antagonist of histaminergic $\mathrm{H}_{1}$-receptor) abolished the accelerating effects of a high dose of histamine on RSNA and BP suggest that a central histaminergic neurotransmission might be involved in the regulation of cardiovascular functions via histaminergic receptors (Tanida et al. 2007b). L-histidine, a component of both L-carnosine and anserine, is converted to histamine in the TMN. In fact, we previously showed that the suppressing or elevating effects of L-carnosine on RSNA and BP were eliminated by pretreatment with thioperamide or diphenhydramine, respectively. This indicates a possible role of histaminergic receptors in L-carnosine activity (Tanida et al. 2005). Thus, it is hypothesized that the effects of anserine on RSNA and BP may also be mediated by the central histamine receptors.

The present study assessed the effects of peripheral administration of various amounts of anserine on RSNA and BP, and evaluated the effects of histaminergic blockers $\left(\mathrm{H}_{3}\right.$ - or $\mathrm{H}_{1}$-receptor antagonist) on changes of the cardiovascular function in urethaneanesthetized rats.

\section{Materials and Methods}

\section{Animals}

Male Wistar rats, weighing 280-330 g were used. Rats were housed in a room maintained at $24 \pm 1{ }^{\circ} \mathrm{C}$ and illuminated for $12 \mathrm{~h}$ (08:00 to 20:00) everyday. Food and water were freely available. Rats were adapted to the environment for at least one week before the experiment. All animal care and handling procedures were approved by the Institutional Animal Care and Use Committee of Osaka University.

\section{General animal preparation}

General preparation was performed as described previously (Tanida et al. 2005). Briefly, on the experimental day, food was removed 4-6 $\mathrm{h}$ before surgery. Anesthesia was induced with an intraperitoneal (IP) injection of $1 \mathrm{~g} / \mathrm{kg}$ urethane, a polyethylene catheter was inserted into the left femoral vein for intravenous (IV) injections, and another catheter was inserted into the left femoral artery for BP determination. The rat was then fixed in a stereotaxic apparatus after a tracheal cannulation. The body temperature was maintained at 37.0-37.5 ${ }^{\circ} \mathrm{C}$ using a heating pad and a thermometer inserted into the rectum. We evaluated the adequacy of the depth of anesthesia by checking every $30 \mathrm{~min}$ throughout the experimental procedure whether rapid variation of BP $( \pm 5 \mathrm{~mm} \mathrm{Hg})$ and $\mathrm{HR}( \pm 10 \%)$ would be caused by paw pinch. If any of these responses was found, a supplemental urethane $(0.1-0.2 \mathrm{~g} / \mathrm{kg})$ was given with an intraperitoneal injection. The depth of anesthesia was maintained stable during experimental period. Using a dissecting microscope, the left renal nerve was exposed retroperitoneally through a left flank incision. The distal end of the nerve was ligated, and then hooked up with a pair of silver wire electrodes for recording the efferent RSNA. The recording electrodes were immersed in a pool of liquid paraffin oil to prevent dehydration and for electrical insulation. The rat was allowed to stabilize for 30-60 min after being placed on the recording electrodes.

Electrical changes in RSNA was amplified 2000-5000 times with a band path of 100 to $1000 \mathrm{kHz}$, and monitored by an oscilloscope. Raw data of the nerve activity was converted to standard pulses by a window discriminator, which separated discharge from electrical background noise which remained post mortem. Both the discharge rates and the neurogram were sampled with a Power-Lab analog-to-digital converter for recording and data analysis on a computer. The catheter in the left femoral artery was connected to a BP transducer (DX-100, Nihon Kohden, Japan), and the output signal of the transducer was amplified in a BP amplifier (AP641G, Nihon Kohden, Japan). Two needle electrodes were placed under the skin at the right arm and left leg to record an electrocardiogram (ECG). The ECG signal was amplified with a bioelectric amplifier (AB-620G, Nihon Kohden, Japan). The BP and ECG were monitored with an oscilloscope, sampled with the Power-Lab, and stored on a hard disk for off-line analysis to calculate mean arterial pressure (MAP) and HR. 


\section{Intracerebroventricular cannulation}

At least one week before the experiment, a brain cannula made of polyethylene tubing (PE-10; Clay Adams, Parsippany, NJ) was inserted into the left lateral cerebral ventricle (A-P, $1.5 \mathrm{~mm}$ caudal to the bregma; $\mathrm{L}, 2.0 \mathrm{~mm}$ lateral to the midline; $\mathrm{V}, 3.0 \mathrm{~mm}$ below the skull surface) under pentobarbital anesthesia $(35 \mathrm{mg} / \mathrm{kg}$, IP) as previously described (Yamamoto et al. 1988). The cannula implanted into the brain was securely fixed by dental cement and synthetic resin. When injections were given to rats, the microsyringe for injection was directly connected to the cannula.

\section{Experimental protocol}

Baseline measurements of RSNA, MAP, and HR were made for $5 \mathrm{~min}$ just before IV injections of anserine $(0.1,1,10,100$ and $1000 \mu \mathrm{g} / 0.1 \mathrm{ml}$ saline $)$ or saline $(0.1 \mathrm{ml})$. In regard to injection doses, those of this study were determined by referring previous observation measurements of plasma levels of anserine (about $50 \mu \mathrm{g} / \mathrm{ml}$ ) in male Wistar rats (Al-Bekairi 1989). After the injection, these parameters were recorded for $60 \mathrm{~min}$. Effects of thioperamide maleate $[20 \mu \mathrm{g} / 10 \mu \mathrm{l}$ artificial cerebrospinal fluid (aCSF); LCV], a histaminergic $\mathrm{H}_{3}$-antagonist, or diphenhydramine hydrochloride $(5 \mu \mathrm{g} /$ $10 \mu \mathrm{laCSF}$; LCV), a histaminergic $\mathrm{H}_{1}$-antagonist, on anserine-induce effects on RSNA, BP and HR were examined. These antagonists were centrally administered $15 \mathrm{~min}$ prior to IV injection of anserine. We previously observed that thioperamide or diphenhydramine alone did not affect RSNA, MAP or HR (Tanida et al. 2006). At the end of the experiment, hexamethonium chloride was intravenously administered $(10 \mathrm{mg} / \mathrm{kg})$ to ensure that the recording was made from postganglionic efferent sympathetic nerve activity.

\section{Data analyses}

The RSNA, MAP, and HR measured during each $5 \mathrm{~min}$ period after the injections of anserine or saline were evaluated by digital signal processing and statistical analyses. All data were expressed as means \pm S.E.M. Because of the inter-individual variability in the preinjection state, percent change from the baseline was also calculated for RSNA. Absolute value changes from the baseline were calculated for MAP and HR. Two-way ANOVA was applied to compare group responses of the RSNA, MAP and HR. To perform statistical analysis of the dose-response to anserine, ANOVA, followed by multiple comparisons using Dunnett's multiple range tests, was used. $\mathrm{P}<0.05$ was considered statistically significant.

\section{Results}

Sample recordings of RSNA and BP before and throughout a $60 \mathrm{~min}$ period following IV injection of saline or anserine are presented in Figure 1A-B. Saline injection did not affect either RSNA or MAP. However, both were suppressed by IV injection of $1 \mu \mathrm{g}$ of anserine, and both were elevated by IV injection of $1000 \mu \mathrm{g}$ of anserine. After the injection of $1 \mu \mathrm{g}$ of anserine, RSNA, MAP and HR were suppressed gradually (Fig. 1C-E), with the greatest level of suppression occurring at 20-60 min. Suppression of RSNA was maintained after reaching its peak. The lowest levels attained were $61.5 \pm 7.3 \%$ (RSNA), $-8.3 \pm 4.2 \mathrm{~mm} \mathrm{Hg}$ (MAP) and $-18 \pm 9$ beats $/ \mathrm{min}$ (HR). Following injection of $1000 \mu \mathrm{g}$ of anserine, RSNA, MAP and HR were elevated depending on a tendency to each acceleration (Fig. 1C-E), with maxima occurring at 25-60 min. The highest levels attained were $179.8 \pm 22.4 \%$ (RSNA), $8.1 \pm 2.5 \mathrm{~mm} \mathrm{Hg}$ (MAP) and $27 \pm 12$ beats/min (HR). In contrast, injection of saline did not cause a significant alteration in the levels of RSNA, MAP and HR. The significance of the differences between values from 5-60 min was analyzed as a group by ANOVA. The following comparisons were made: RSNA: Saline vs. anserine $(1 \mu \mathrm{g}), \mathrm{P}<0.01 \quad(\mathrm{~F}=30.5)$; saline vs. anserine $(1000 \mu \mathrm{g}), \mathrm{P}<0.01 \quad(\mathrm{~F}=12.8)$; MAP: Saline vs. anserine $(1 \mu \mathrm{g}), \mathrm{P}<0.05 \quad(\mathrm{~F}=8.9)$; saline vs. anserine $(1000 \mu \mathrm{g}), \mathrm{P}<0.05 \quad(\mathrm{~F}=6.6)$. HR: Saline vs. anserine $(1 \mu \mathrm{g}), \mathrm{P}<0.05 \quad(\mathrm{~F}=5.5)$; saline vs. anserine $(1000 \mu \mathrm{g}), \quad \mathrm{P}<0.05 \quad(\mathrm{~F}=6.0)$. Absolute basal $(0 \mathrm{~min})$ RSNA, MAP and HR values for the experiments shown in Figure 1 are summarized in Table 1. Differences in respective basal values were not statistically significant (Mann-Whitney U test).

Sixty minutes after the IV injection of lower dose of anserine $(0.1 \mu \mathrm{g})$, the levels of RSNA, MAP and HR decreased (Fig. 2A-C). The maximum suppressive responses occurred after the injection of $1 \mu \mathrm{g}$ of anserine. In contrast, at $60 \mathrm{~min}$, the higher dose of anserine $(1000 \mu \mathrm{g})$ significantly increased RSNA, MAP and HR. Absolute basal (0 min) RSNA, MAP and HR values for the experiments shown in Figure 2 are summarized in Table 1. Differences in respective basal values were not statistically significant (Mann-Whitney U test). 
(A)

RSNA

saline
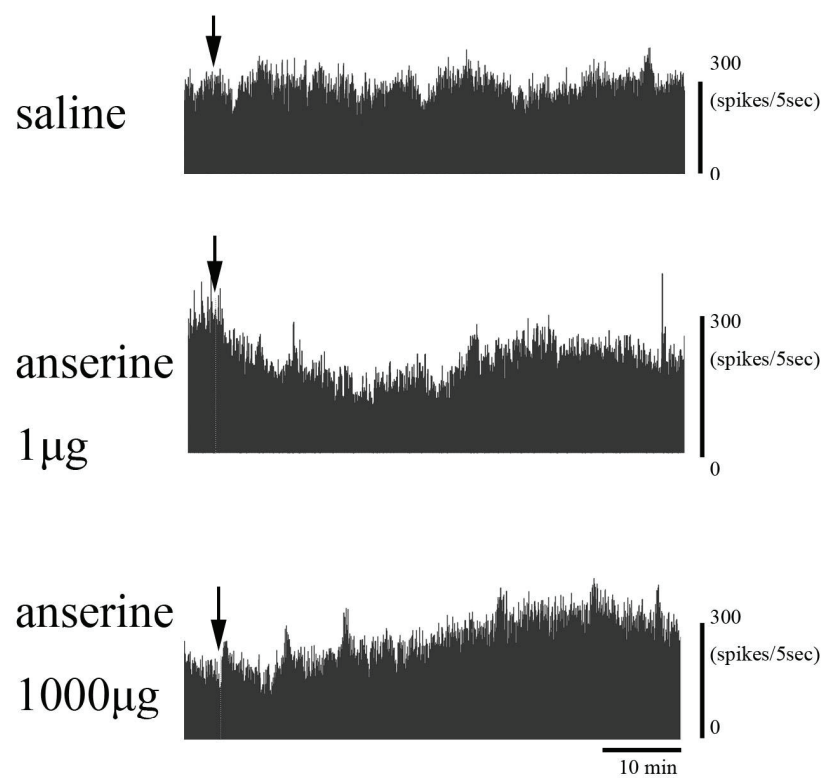

(B)

BP
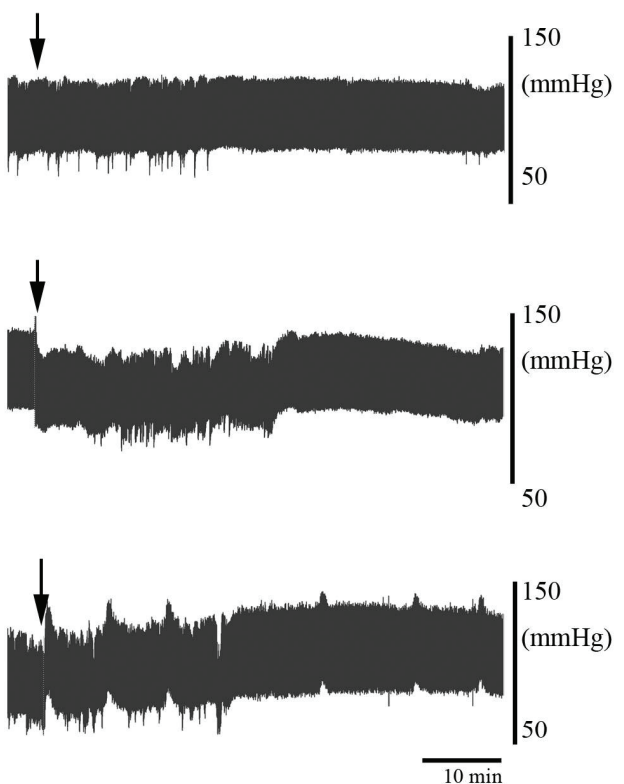

(C)

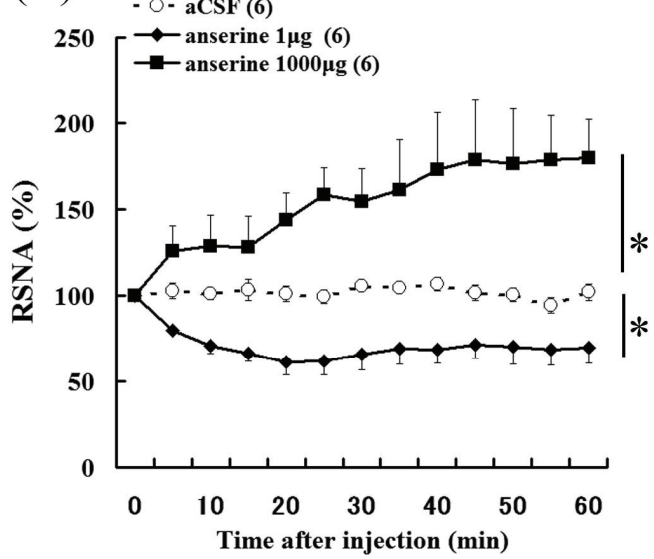

(D)

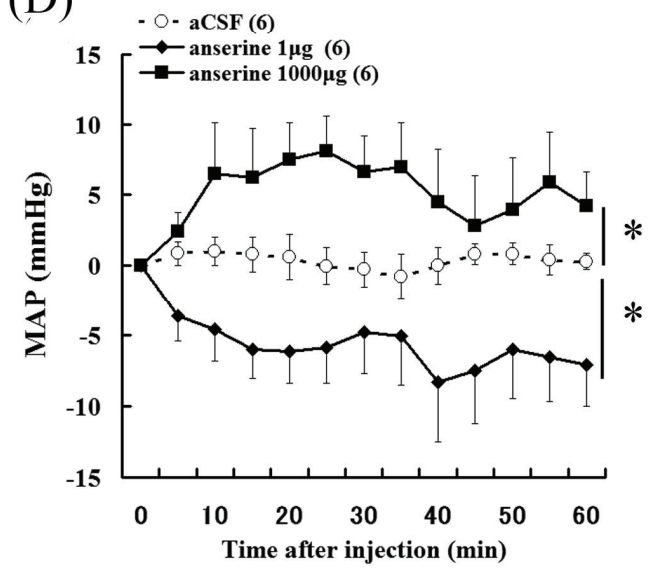

(E)

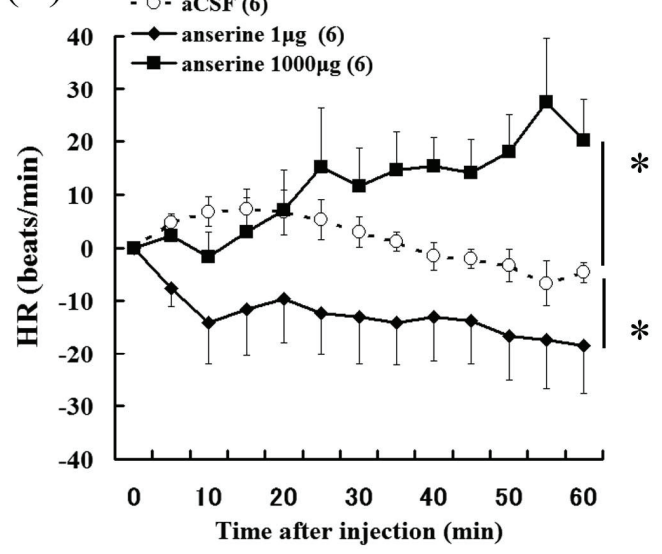

Fig. 1. Effects of IV injection of anserine on the renal sympathetic nerve activity (RSNA), blood pressure (BP) and heart rate (HR). Representative trace data from recordings of RSNA (A) and BP (B) before and after the IV injection of saline or anserine $(1 \mu \mathrm{g}$ and $1000 \mu \mathrm{g})$. Time-course data of RSNA (C), MAP (D) and HR (E) after IV injection of saline or anserine (1 $\mu \mathrm{g}$ and $1000 \mu \mathrm{g})$ are expressed as mean \pm S.E.M. * Significant differences between saline group and anserine groups $(P<0.05)$. 

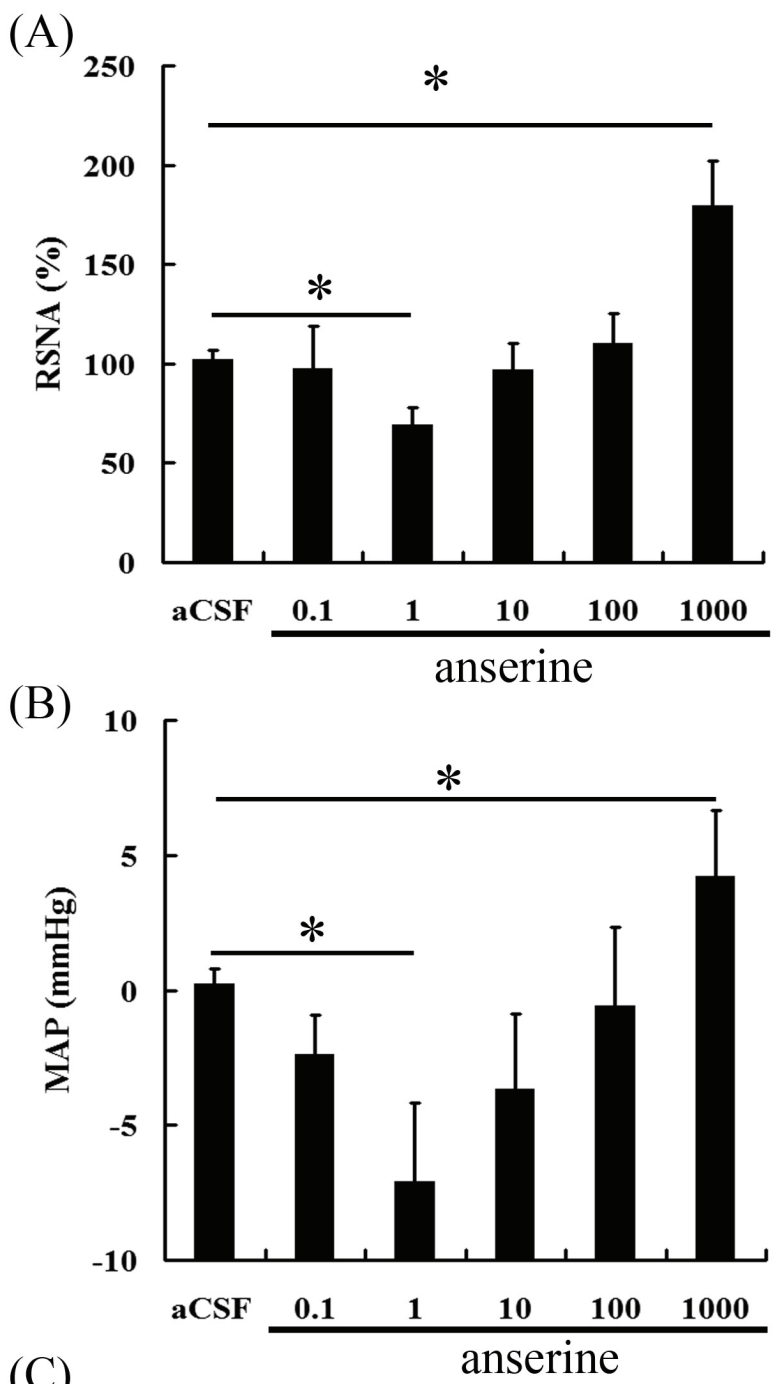

(C)



Fig. 2. Dose-dependent effects of IV injection of anserine on the RSNA, MAP and HR. Bars in A, B and C show RSNA, MAP and HR values 60 min after injection of five doses $(0.1,1,10,100$ and $1000 \mu \mathrm{g})$ of anserine and saline. Numbers of animals used in each group are 6 rats. *Significant differences between saline group and anserine groups $(P<0.05)$.
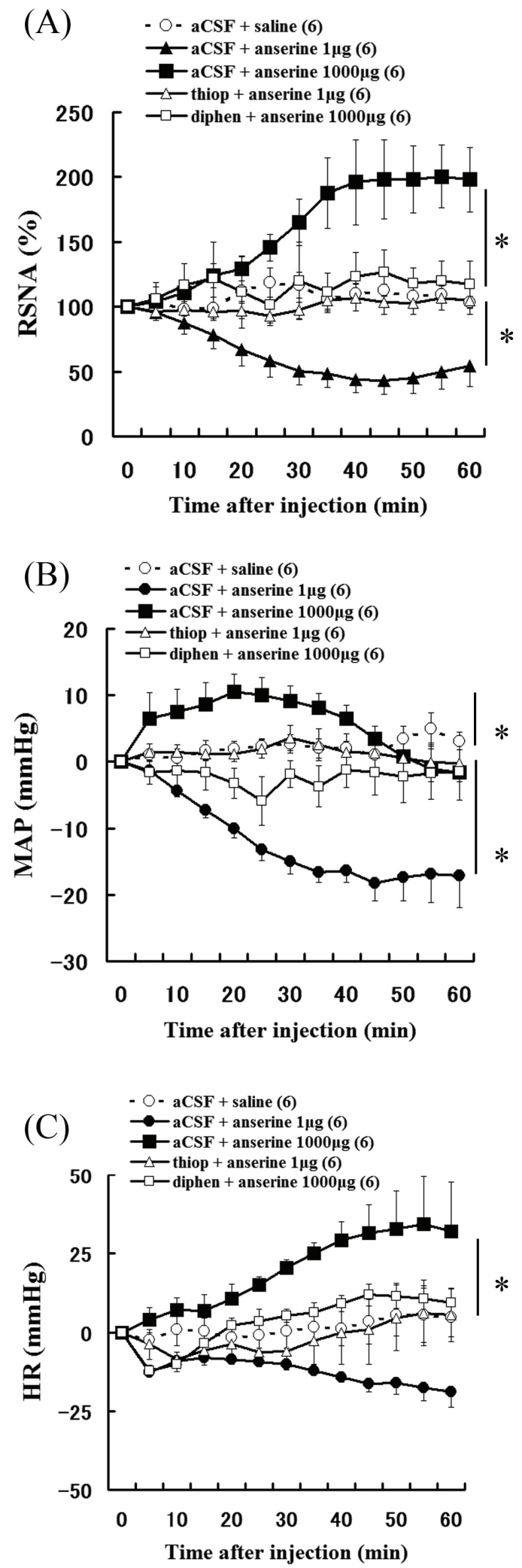

Fig. 3. Effects of thioperamide and diphenhydramine on changes in RSNA, MAP and HR following IV injection of $1 \mu \mathrm{g}$ and $1000 \mu \mathrm{g}$ of anserine. RSNA (A), MAP (B) and HR (C) after IV injection of saline $(0.1 \mathrm{ml})$ or anserine $(1 \mu \mathrm{g}$ or $1000 \mu \mathrm{g})$ are expressed as mean \pm S.E.M. LCV injection of aCSF, thioperamide (thiop) or diphenhydramine (diphen) were given 15 min before IV injection of either saline or anserine. Significant differences between control group (aCSF \pm saline) and anserine groups (aCSF \pm anserine $1 \mu \mathrm{g}$ or $1000 \mu \mathrm{g})$ were analyzed by ANOVA $(P<0.05)$. 
Table 1. Basal levels of the RSNA, MAP and HR in the groups of rats.

\begin{tabular}{|c|c|c|c|c|}
\hline & $\mathbf{n}$ & $\begin{array}{c}\text { RSNA } \\
\text { (spikes/s) }\end{array}$ & $\begin{array}{c}\text { MAP } \\
(\mathbf{m m ~ H g})\end{array}$ & $\begin{array}{c}\text { HR } \\
\text { (beats/min) }\end{array}$ \\
\hline \multicolumn{5}{|l|}{ Groups of Figure 1 and Figure 2} \\
\hline$a C S F$ & 6 & $119.8 \pm 31.6$ & $94.6 \pm 7.2$ & $362 \pm 54$ \\
\hline anserine $0.1 \mu \mathrm{g}$ & 6 & $195.9 \pm 22.2$ & $94.6 \pm 9.5$ & $358 \pm 37$ \\
\hline anserine $1 \mu \mathrm{g}$ & 6 & $178.8 \pm 24.1$ & $95.2 \pm 9.0$ & $389 \pm 18$ \\
\hline anserine $10 \mu \mathrm{g}$ & 6 & $228.7 \pm 75.8$ & $100.9 \pm 9.7$ & $390 \pm 18$ \\
\hline anserine $100 \mu \mathrm{g}$ & 6 & $200.4 \pm 18.8$ & $86.9 \pm 10.7$ & $369 \pm 23$ \\
\hline anserine $1000 \mu \mathrm{g}$ & 6 & $259.6 \pm 96.3$ & $92.2 \pm 5.6$ & $353 \pm 32$ \\
\hline \multicolumn{5}{|l|}{ Groups of Figure 3} \\
\hline$a C S F+$ saline & 6 & $136.3 \pm 26.5$ & $80.7 \pm 7.1$ & $363 \pm 26$ \\
\hline aCSF + anserine $1 \mu \mathrm{g}$ & 6 & $131.4 \pm 7.2$ & $88.5 \pm 8.5$ & $371 \pm 13$ \\
\hline aCSF + anserine $1000 \mu \mathrm{g}$ & 6 & $168.6 \pm 22.5$ & $85.2 \pm 6.5$ & $332 \pm 23$ \\
\hline thioperamide + anserine $1 \mu \mathrm{g}$ & 6 & $150.1 \pm 22.0$ & $86.7 \pm 8.6$ & $405 \pm 13$ \\
\hline diphenhydramine + anserine $1000 \mu g$ & 6 & $148.6 \pm 21.4$ & $88.9 \pm 10.9$ & $372 \pm 13$ \\
\hline
\end{tabular}

RSNA - renal sympathetic nerve activity; MAP - mean arterial pressure; HR - heart rate. Data are presented means \pm S.E.M., $n=$ number of rats.

To clarify the role of histaminergic receptors in anserine action in this study, responses of RSNA, MAP and HR to IV injections of anserine were compared between aCSF-control group and groups given injection of thioperamide or diphenhydramine. RSNA and MAP were found to be significantly reduced by $1 \mu \mathrm{g}$ of anserine and elevated by IV injection of $1000 \mu \mathrm{g}$ of anserine in aCSF pretreated rats (Fig. 3A, B). HR was significantly elevated by IV injection of $1000 \mu \mathrm{g}$ of anserine in aCSF pretreated rats (Fig. 3C). Pre-treatment with thioperamide or diphenhydramine eliminated the effects of IV injection of low- or high-doses of anserine, respectively for LCV experimental groups (Fig. 3A-C). The significance of the differences between values from 5-60 min analyzed as a group by ANOVA, is as follows: RSNA: aCSF-saline vs. aCSF-anserine $(1 \mu \mathrm{g}), \mathrm{P}<0.01$ $(\mathrm{F}=17.7)$; aCSF-saline vs. aCSF-anserine $(1000 \mu \mathrm{g})$, $\mathrm{P}<0.05(\mathrm{~F}=8.6)$; aCSF-anserine $(1 \mu \mathrm{g})$ vs. thioperamideanserine $\quad(1 \mu \mathrm{g}), \quad \mathrm{P}<0.01 \quad(\mathrm{~F}=14.1) ; \quad$ aCSF-anserine $(1000 \mu \mathrm{g}) \quad$ vs. diphenhydramine-anserine $(1000 \mu \mathrm{g})$, $\mathrm{P}<0.05 \quad(\mathrm{~F}=4.6) . \quad$ MAP: aCSF-saline vs. aCSF-anserine $(1 \mu \mathrm{g}), \mathrm{P}<0.005$ ( $\mathrm{F}=63.7)$; aCSF-saline vs. aCSF-anserine $(1000 \mu \mathrm{g}), \mathrm{P}<0.05(\mathrm{~F}=4.2)$; aCSF-anserine $(1 \mu \mathrm{g})$ vs. thioperamide-anserine $(1 \mu \mathrm{g}), \mathrm{P}<0.005(\mathrm{~F}=40.9)$; aCSFanserine $(1000 \mu \mathrm{g}) \quad$ vs. diphenhydramine-anserine $(1000 \mu \mathrm{g}), \mathrm{P}<0.05(\mathrm{~F}=6.6)$. HR: aCSF-saline vs. aCSFanserine $(1 \mu \mathrm{g})$, N.S. $\mathrm{P}=0.05<0.1 \quad(\mathrm{~F}=2.8)$; aCSF-saline vs. aCSF-anserine $(1000 \mu \mathrm{g}), \mathrm{P}<0.05 \quad(\mathrm{~F}=6.2)$; aCSF- anserine $(1 \mu \mathrm{g})$ vs. thioperamide-anserine $(1 \mu \mathrm{g}), \mathrm{P}<0.05$ $(\mathrm{F}=8.4)$; aCSF-anserine $(1000 \mu \mathrm{g})$ vs. diphenhydramine anserine $(1000 \mu \mathrm{g}), \mathrm{P}<0.05 \quad(\mathrm{~F}=3.1)$. Absolute basal (0 min) RSNA, MAP and HR values for the experiments shown in Figure 3 are summarized in Table 1. Differences in respective basal values were not statistically significant (Mann-Whitney U test).

\section{Discussion}

Several dipeptides released from mammalian skeletal muscle into the blood are thought to be beneficial for health. Our previous studies revealed that peripheral injection of L-carnosine showed bioactive effects, e.g. it affects autonomic nerves, and regulates BP, blood glucose concentrations, and body temperature (Yamano et al. 2001, Tanida et al. 2005, 2007a). However, the effects of anserine and other dipeptides on autonomic nerve and cardiovascular functions have not been studied in vivo yet. Present study showed that intravenous injection of a low dose of anserine reduced RSNA, BP, and HR in anesthetized rats (Fig. 1). In addition, a high dose of anserine accelerated the RSNA, BP, and HR in anesthetized rats. This novel finding indicates that anserine induces autonomic and cardiovascular responses in a dose-dependent manner, which is similar to the effects of L-carnosine (Tanida et al. 2005). Furthermore, because the autonomic and cardiovascular systems are 
modulated by the brain, the central mechanism responsible for the action of anserine was also investigated. It was found that LCV treatment with central histamine receptor blockers such as thioperamide or diphenhydramine significantly eliminated the changes in RSNA, BP, and HR elicited by low or high doses of anserine (Fig. 3). Thus, our data suggest that anserine might act in the brain, and affect the sympathetic and cardiovascular functions via the central pathway of histaminergic neurotransmission.

In the present study, the biphasic effects of anserine on RSNA, BP, and HR lasted for a long time after anserine injection (Fig. 1). It is generally accepted that anserine released from skeletal muscle into the blood is hydrolyzed by carnosinase, resulting in L-histidine and $\beta$-alanine (Lenney 1976, Pegova et al. 2000). Because L-histidine is taken up by histaminergic neurons in the brain for the synthesis and release of histamine, it is thought that the long-lasting effects of anserine might be induced via the central histaminergic mechanism. Our observations that LCV injections of various doses of histamine result in long-term changes in RSNA and BP (Tanida et al. 2007b), and that the biphasic effects of anserine on sympathetic and cardiovascular responses are abolished by pretreatment with histaminergic antagonists (Fig. 3) strongly support the theory that long-lasting effects of anserine might be induced via the central histaminergic mechanism.

In the present study, LCV pretreatment with the histamine antagonist thioperamide eliminated the suppressive effects of $1 \mu \mathrm{g}$ anserine on RSNA and BP, and pretreatment with the histamine antagonist diphenhydramine eliminated the elevating effects of 1000 $\mu \mathrm{g}$ anserine (Fig. 3). These findings suggest that the suppressive and elevating effects of anserine on RSNA and BP might be mediated by histamine $\mathrm{H}_{3}$ - and $\mathrm{H}_{1}$ receptors, respectively. With regards to signal transduction in the synapse of neurons containing histamine, the presynaptic $\mathrm{H}_{3}$-receptors mediate the autoinhibition of histamine release from the histaminergic neurons to the synaptic clefts. Affinity of $\mathrm{H}_{3}$-receptors for histamine is much higher than the affinities of the postsynaptic histamine $\mathrm{H}_{1}$ - and $\mathrm{H}_{2}$-receptors (Arrang et al. 1983). Therefore, a small amount of histamine suppresses histamine release from the presynaptic histaminergic neurons via the $\mathrm{H}_{3}$-receptor. However, a large amount of histamine transmits histaminergic neural signals via the $\mathrm{H}_{1}$-receptor. In fact, our previous study showed that the cardiovascular effects of the central injection of low- or high-dose histamine were inhibited by pretreatment with thioperamide or diphenhydramine (Tanida et al. 2007b). This observation indicates a role of central histamine receptors in sympathetic and cardiovascular regulation. Thus, on the basis of our findings, we suggest that anserine might act in the brain, and cause the autonomic nerves to modulate cardiovascular functions via the histaminergic neurons. Because the effect of anserine injection on histamine release in the hypothalamus was not examined, microdialysis study focusing on the hypothalamic release of histamine after anserine injection might be helpful to determine the precise role of histaminergic mechanism on cardiovascular responses to anserine.

Present study has several limitations that need to be addressed. First, anesthetized rats were used in the study; therefore, it is possible that the results would have been different if freely moving, conscious rats had been used. The effects of anserine on conscious rats were not determined in the study because it was difficult to measure RSNA in conscious rats. However, in our previous study of both unanesthetized and anesthetized rats, low-dose administration of L-carnosine suppressed hyperglycemia induced by 2-deoxy-D-glucose (2DG) in conscious rats, and enhanced the activity of celiac parasympathetic nerves in urethane-anesthetized rats (Yamano et al. 2001). In addition, our preliminary study confirmed that peripheral administration of a low dose of anserine inhibited 2DG-induced hyperglycemia in freely moving rats, and activated the gastric parasympathetic nerves in urethane-anesthetized rats (unpublished data). Thus, it is possible that there is little effect of anesthesia on the sympathetic and cardiovascular responses to anserine. Second, in the present study, the effects of anserine on neural activity of the parasympathetic nerve branches were not investigated. With respect to the role of parasympathetic nerves in blood glucose regulation, the parasympathetic nerves stimulate the glucose metabolism in the pancreas and liver via insulin release and glycogen synthesis, respectively. In general, elevated parasympathetic nerve activity results in a reduction of blood glucose concentrations via increases in insulin release and glycogen synthesis. In support of this observation, the injection of a low dose of L-carnosine was shown to reduce adrenal sympathetic nerve activity and increase celiac parasympathetic nerve activity (Yamano et al. 2001) after the suppression of 2DG-induced hyperglycemia. Our preliminary observation that peripheral administration of a low dose 
of anserine inhibited 2DG-induced hyperglycemia, and increased parasympathetic nerve outflow to the stomach (unpublished data), suggests a possible role of anserine in parasympathetic control. Third, the effects of anserine on the autonomic center of the hypothalamus were not determined. However, the suprachiasmatic nucleus $(\mathrm{SCN})$, one of the hypothalamic nuclei and a master circadian oscillator, plays an important role in the control of glucose metabolism, and BP via the regulation of the autonomic nervous system (Nagai K et al. 1996, Tanida et al. 2005). Furthermore, the bilateral lesions of the SCN have been shown to completely eliminate the responses of both RSNA and BP to L-carnosine (Tanida et al. 2005), which suggests that the SCN might be one of the regions of L-carnosine activity. Therefore, the SCN might not only be involved in the above mentioned mechanisms, but may also be involved in the mechanisms responsible for the effects of anserine on RSNA and BP.
Precise investigations such as the study of electric lesion or a microinjection study might be helpful to determine the action area in the hypothalamus during cardiovascular responses to anserine.

In conclusion, present findings suggest that anserine affects RSNA, BP, and HR in a dose-dependent manner. The histaminergic nervous system in the brain might be involved in the mechanism responsible for these effects. However, further study is required to determine the precise pathway responsible for the effects of anserine on sympathetic and cardiovascular system functions.

\section{Conflict of Interest}

There is no conflict of interest.

\section{Acknowledgements}

We deeply thank Dr. Akira Niijima for his technical support.

\section{References}

AL-BEKAIRI AM: Effect of hypoxia and/or cold stress on plasma and brain amino acids in rat. Res Commun Chem Pathol Pharmacol 64: 287-297, 1989.

ARRANG JM, GARBARG M, SCHWARTZ JC: Auto-inhibition of brain histamine release mediated by a novel class (H3) of histamine receptor. Nature 302: 832-837, 1983.

DRUMMOND JC: The nitrogenous extractives of tumours. Biochem J 11: 246-254, 1917.

JOHNSON P, HAMMER JL: Histidine dipeptide levels in ageing and hypertensive rat skeletal and cardiac muscle. Comp Biochem Physiol B 103: 981-984, 1992.

LENNEY JF: Specificity and distribution of mammalian carnosinase. Biochim Biophys Acta 429: 214-219, 1976.

LO HI, TSI D, TAN AC, WANG SW, HSU MC: Effects of postexercise supplementation of chicken essence on the elimination of exercise-induced plasma lactate and ammonia. Chin J Physiol 48: 187-192, 2005.

MATSUMURA Y, KITA S, ONO H, KISO Y, TANAKA T: Preventive effect of a chicken extract on the development of hypertension in stroke-prone spontaneously hypertensive rats. Biosci Biotechnol Biochem 66: 1108-1110, 2002.

MORGAN DA, ANDERSON EA, MARK AL: Renal sympathetic nerve activity is increased in obese Zucker rats. Hypertension 25: 834-838, 1995.

NAGAI H, HARADA M, NAKAGAWA M, TANAKA T, GUNADI B, SETIABUDI ML, UKTOLSEJA JL, MIYATA Y: Effects of chicken extract on the recovery from fatigue caused by mental workload. Appl Human Sci 15: 281-286, 1996.

NAGAI K, NAGAI N, SHIMIZU K, CHUN S, NAKAGAWA H, NIIJIMA A: SCN output drives the autonomic nervous system: with special reference to the autonomic function related to the regulation of glucose metabolism. Prog Brain Res 111: 253-272, 1996.

OTANI H, OKUMURA N, HASHIDA-OKUMURA A, NAGAI K: Identification and characterization of a mouse dipeptidase that hydrolyzes L-carnosine. J Biochem (Tokyo) 137: 167-175, 2005.

PEGOVA A, ABE H, BOLDYREV A: Hydrolysis of carnosine and related compounds by mammalian carnosinases. Comp Biochem Physiol B Biochem Mol Biol 127: 443-446, 2000.

SATO M, KARASAWA N, SHIMIZU M, MORIMATSU F, YAMADA R: Safety evaluation of chicken breast extract containing carnosine and anserine. Food Chem Toxicol 46: 480-489, 2008. 
TANIDA M, NIIJIMA A, FUKUDA Y, SAWAI H, TSURUOKA N, SHEN J, YAMADA S, KISO Y, NAGAI K: Dose-dependent effects of L-carnosine on the renal sympathetic nerve and blood pressure in urethaneanesthetized rats. Am J Physiol 288: R447-R455, 2005.

TANIDA M, NIIJIMA A, SHEN J, YAMADA S, SAWAI H, FUKUDA Y, NAGAI K: Dose-different effects of orexin-A on the renal sympathetic nerve and blood pressure in urethane-anesthetized rats. Exp Biol Med (Maywood) 231: 1616-1625, 2006.

TANIDA M, GOTOH H, TANIGUCHI H, OTANI H, SHEN J, NAKAMURA T, TSURUOKA N, KISO Y, OKUMURA N, NAGAI K: Effects of central injection of L-carnosine on sympathetic nerve activity innervating brown adipose tissue and body temperature in rats. Regul Pept 144: 62-71, 2007a.

TANIDA M, KANEKO H, SHEN J, NAGAI K: Involvement of the histaminergic system in renal sympathetic and cardiovascular responses to leptin and ghrelin. Neurosci Lett 413: 88-92, 2007b.

WATANABE T, TAGUCHI Y, SHIOSAKA S, TANAKA J, KUBOTA H, TERANO Y, TOHYAMA M, WADA H: Distribution of the histaminergic neuron system in the central nervous system of rats; a fluorescent immunohistochemical analysis with histidine decarboxylase as a marker. Brain Res 295: 13-25, 1984.

YAMAMOTO H, NAGAI K, NAKAGAWA H: Time-dependent involvement of autonomic nervous system in hyperglycemia due to 2-deoxy-D-glucose. Am J Physiol 255: E928-E933, 1988.

YAMANO T, NIIJIMA A, IIMORI S, TSURUOKA N, KISO Y, NAGAI K: Effect of L-carnosine on the hyperglycemia caused by intracranial injection of 2-deoxy-D-glucose in rats. Neurosci Lett 313: 78-82, 2001. 